\title{
A Chromosomal Survey of Some Indian Insects ${ }^{1}$ \\ IV. On the sex chromosomes of some species of beetles (Coleoptera) ${ }^{2}$
}

By

\section{J. J. Asana, S. Makino and $\boldsymbol{H}$. Niiyama}

Zool. Institute, Faculty of Science,

Hokkaido Imp. University, Sapporo

(With 54 figures)

Ficciz al Ausist $12,19+1$

This paper deals with the chromosomes of seven species of Coeleopterous insects obtained in India, with particular reference to the morphology of the sex chromosomes. Six out of these seven species come under the division Polyphaga, while the remaining one belongs to Adephaga. Their names and systematic positions are given below. So far as the literature is accessible, starting with the study of Henking in 1892, over a hundred species have been karyologically studied in this group of insects, and these investigations include more or less detailed accounts of their chromosomes. In spite of this considerable amount of cytological study in this group, very few of these accounts include an accurate analysis of the sex chromosomes and their behaviour. Because of much doubtful and conflicting evidence that has appeared in previous studies, we believe renewed inrestigations on this aspect of chromosomal studies in Coeleoptera are necessary. In this respect, Schrader ('28) states that in the majority of cases where sex chromosomes have been described in Coeleoptera since 1905, no complete analysis has been made. He thinks it probable that a certain amount of confusion as to the details in regard to the sex chromosomes in this order is largely attributable to superficial work. Bearing these observations in mind, in the present study the number of chromosomes and the constitution and behaviour of the sex chromosomes of the seren species have been closely investigated and compared with the known cases. A new finding in this study, it may perhaps be of interest to notice here, is the attachment of the $\mathrm{X}$ chromosome to an autosome found in the three species of the Buprestidae studied.

1 Of this series of investigation the following articles have already been published: I. Morphology of the chromosomes in eight species of the Locustidae (Jour. Fac. Sci. Hokkaido Imp. Univ. Ser. VI, Zool. 6, 1938). II. A comparative study of the chromosomes in six species of Acrididae (Jap. Jour. Genet. 15, 1939). III. Variations in the chromosome number of Gryllotalpa africana due to the inclusion of supernumerary chromosomes (Jour. Fac. Sci. Hokkaido Imp. Univ. Ser. VI, Zool. 7, 1940).

2 Contribution No. 156 from the Zoological Institute, Faculty of Science, Hokkaido Imperial University, Sapporo, Japan. 
The authors express their sincere appreciation of helpful suggestions and criticism offered by Prof. K. Oguma during the course of the study.

\section{Material and Method}

Testes from specimens collected in the vicinity of the Gujarat College, Ahmedabad, Western India, comprise the material for this study, All the specimens were collected and their gonads fixed between July 1938 and November 1939. The fixative used in all cases, excepting Anthia, the testes of which were fixed in Allen-Bouin, was a modification of Flemming. To every 3 c.c. of a solution obtained by diluting strong Flemming with half its quantity of distilled water a drop of glacial acetic acid was added at the time of fixing. Sections were cut 8 to 10 micra in thickness and stained with Heidenhain's iron-haematoxylin accompanied by light green. The figures were drawn with the aid of a camera lucida using a Zeiss $2 \mathrm{~mm}$. objective and K 20 ocular.

All the dissected specimens were identified by Dr. Y. Miwa, the specialist in the Department of Agriculture, Government Research Institute, Formosa, to whom grateful thanks are due for this very troublesome task. The species identified are arranged as follows:

Suborder PoLyPhaGA

I. Family Meloidae

1. Mylabris pustulata

2. Meloe sp.

II. Family Hydrophilidae

3. Hydrous acuminatus
III. Family Buprestidae

4. Sternocera nitidicolis

5. Sternocera laevigata

6. Julodis whithilli

Suborder ADEPHAGA

IV Family CARABIDAE

7. Anthia sexguttata

\section{Observations}

Suborder PoLYPHAGA

\section{Family Meloidae}

An account of the chromosomes in the two species of this family, Epicauta cinerea and $E$. pennsylvanica, has already been published by Stevens ('09). In the present study two other species of the same family are examined.

\section{Mylabris pustulata}

The spermatogonial metaphase shows 22 chromosomes (as 2n), including an unequal pair formed by the $\mathrm{X}$ and $\mathrm{Y}$ elements (Figs. 1-2). The majority of the autosomal elements, 5 pairs at least, are provided with clear constrictions suggesting the atelomitic attachment of the spindle fibres. The even number of chromosomes in this species suggests the 
existence of the sex chromosomes of the $\mathrm{X}-\mathrm{Y}$ type. In an attempt to pair the supposed homologous mates of chromosomes, one can make out the $\mathrm{X}$ element which is represented by one of the medium sized chromosomes atelomitic in na-
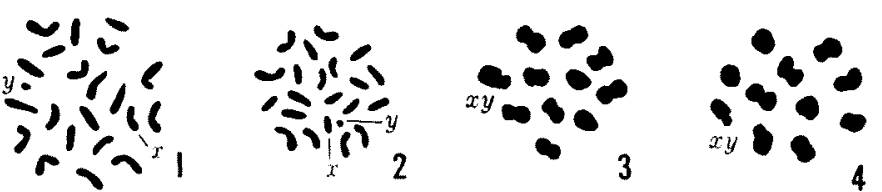
ture which seems to be nearly equal in size to the 8th pair of autosomes, while the $\mathrm{Y}$ is a minute spheroidal body, quite conspicuous among the complement. The $\mathrm{X}$ assumes no parti-

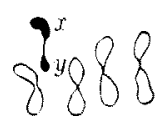

5
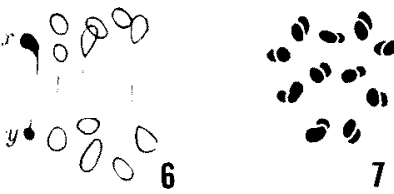

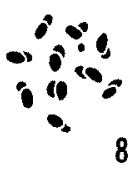

Figs. 1-8. Chromosomes of Mylabris pustulate. ×3700. 1-2, Spermatogonial metaphases. 3-4, Primary spermatocyte metaphases. 5-6, Side views of the primary spermatocyte metaanaphases. 7, Secondary spermatocyte, X-class. 8, The same, Y-class.

cular feature to make it distinguishable from other chromosomes in the complement.

The primary spermatocyte contains at metaphase 11 well-defined chromosomes (as $n$ ), consisting of 10 autosomal bivalents and a heteromorphic bivalent composed of the $\mathrm{X}$ and $\mathrm{Y}$ (Figs. 3-4). The latter lies always at the periphery of the equatorial plate and it can be seen in its entirety better in a side view of the spindle than in the polar riew. The $\mathrm{X}$ conjugates with the $\mathrm{Y}$ by means of an end-to-end attachment. In the first division all the bivalents, including the XY, segregate into their component halves, the $\mathrm{X}$ and $\mathrm{Y}$ migrating towards the opposite poles (Figs. 5-6). Consequently, two kinds of secondary spermatocytes are produced as regards the $\mathrm{X}$ and $\mathrm{Y}$ elements, though the number of chromosomes is eleven in both, the one containing the $\mathrm{X}$ (Fig. 7) while the other possesses the $\mathrm{Y}$ (Fig. 8).

\section{Meloe sp.}

The diploid number of chromosomes as counted in the spermatogonial division was determined to be 20 , two less than that of the former species. The diploid complex consists of 18 autosomal chromosomes in 9 pairs and an unequal pair consisting of the $\mathrm{X}$ and $\mathrm{X}$ elements (Figs. 9-10). As seen in the accompanying figures, 3 or 4 pairs of autosomes seem to be characterized by distinct constrictions indicating atelomitic structure. By picking up the homologous mates of chromosomes by comparing their size and shape, the $\mathrm{X}$ chromosome is identified as that body which is very similar in size and shape to the smallest pair of autosomes, and the $Y$ as a minute spheroidal element. These 20 chromosomes are converted into 

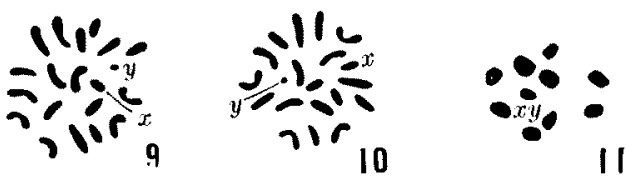

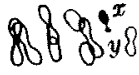

12

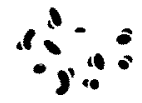

13

10 bivalents in the primary spermatocyte (Fig. 11), composed of 9 autosomal tetrads and a heteromorphic $\mathrm{XY}$ bivalent, the $\mathrm{X}$ and $\mathrm{Y}$ conjugating end-toend at their free extremities (Fig. 12). The XY bivalent lies at the metaphase either at the periphery or in the inner area of the spindle surrounded by the other tetrads. The primary spermatocyte division results into two kinds of secondary spermatocytes, each having 10 chrono-

Figs. 9-14. Chromosomes of Meloe sp. $\times 3700$. 9-10, Spermatogonial metaphases. 11, Primary spermatocyte metaphase. 12, Side view of the primary spermatocyte metaphase. 13, Secondary spermatocyte metaphase, X-class. 14, The same, Y-class.

somes, one of the two daughter cells includes the $\mathrm{X}$ element (Fig. 13) and the other the $\mathrm{Y}$ (Fig. 14).

Remarks:- In the general features of their chromosomes when comparison is made between the two species above described, it is found that this two species are nearly related to each other, the main difference being in the number of chromosomes, Mylabris possessing two more than Meloe. The type of the sex chromosomes is also the same, the XY condition being present in both. But in respect of the morphological features of the $\mathrm{X}$. the two species are not similar. In Mylabris the $\mathrm{X}$ is represented by a medium sized, atelomitic element, whereas in Meloe it is rod shaped, corresponding in length to the smallest autoscmal pair. Close comparison has revealed no other differences in the morphological features of the autosomal chromosomes between the two species.

As noted above, an account of the chromosomes of two species of Meloidae, Epicanta cinerea and E. pennsylvanica, has been published by Stevens ('09). In number the chromosomes of these two species are alike being 20 in diploid and 10 in haploid. The chromosomal garnitures in both these species contain an unequal pair of sex chromosomes, composed of a large $\mathrm{X}$ and a small $\mathrm{Y}$ of minute size. Referring to the figures given by Stevens ('09) and by comparing them with our observations one finds that in apparent morphological features of its chromosomes the genus Epicauta, as represented by these two species, is closely analogous to Meloe, as it is also in the number of its chromosomes and in its sex chromosome condition. More detailed comparison, however, is impossible as the description concerning Epicauta given by Stevens ('09) is too brief to merit further consideration.

\section{Family Hydrophilidae}

The chromosomes of only one species of this family are known.

1 In Harvey's list published in 1916 some 20 species are enumerated under the Fam. Hydrophilidae, but this systematic arrangement has been proved to be erroneous. Almost all species listed there are those belonging to Eam. Chrysomelidae, Hydrophitus picens being the only nember of Hydrophilidae. 
Carnoy ('85) and vom Rath ('92) early gave brief accounts of the chromosomes of Hydrophilus piceus, and later Arnold ('08) renewed the investigations on the same species in greater detail. In the present paper an account is given of the chromosomes of Hydrous acuminatus which belongs to the same sub-family Hydrophilinae.

\section{Hydrous acuminatus}

In spite of the small cell size in this species the number of chromosomes is considerably high. A careful examination shows that the spermatogonial metaphase contains 30 chromosomes (Figs. 15-16), and each of the 25 elements among them bears a clear constriction near its middle portion, indicating an atelomitic fibre attachment, while the remaining five elements are rodshaped and telomitic, one being remarkably minute in size. The even number of chromosomes suggests the existence of the $\mathrm{XY}$ sex-chromosome. By pairing the homologous mates, as usual, according to their comparable shape and size, it becomes evident that one of the larger atelomitic chromosomes remains un-
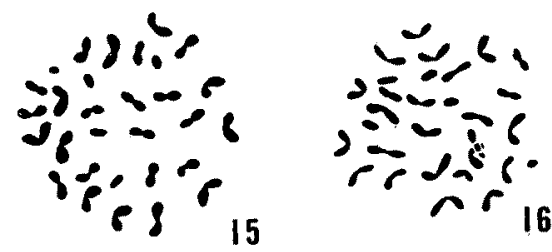

\section{6}

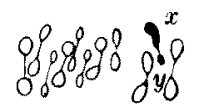

18

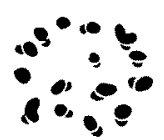

19

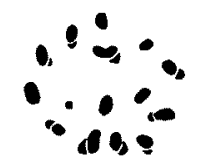

20

Figs. 15-20. Chromosomes of Hydrous acuminatus. $\times 3700$. 15-16, Spermatogonial metaphases. 17, Primary spermatocyte metaphase, 18, Side view of the primary spermatocyte meta-anaphase, 19, Secondary spermatocyte metaphase, $X$ class. 20, The same, Y-class, paired, which is most probably the $\mathrm{X}$ chromosome, while in the telomitic group four are arranged into two homologous pairs, the remaining minute body being the $Y$. As the $\mathrm{X}$ element possesses no particularly distinguishable character, it is difficult to be made out among the diploid members.

Fourteen autosomal bivalents and a heteromorphic bivalent composed of the $\mathrm{X}$ and $\mathrm{Y}$ constitute the metaphase plate of the primary spermatocyte (Fig. 17). The XY bivalent always takes a peripheral position in the equatorial arrangement and the conjugation of the $\mathrm{X}$ and $\mathrm{Y}$ takes the form of an end-to-end attachment, as seen in a side view of the spindle (Fig. 18). The $\mathrm{X}$ and $\mathrm{Y}$ segregate as usual in the first division without exception, and there result two sorts of secondary spermatocytes as regards the distribution of the $\mathrm{X}$ and $\mathrm{Y}$ chromosomes. One of them is the $X$-class cell having the $X$ in its complex (Fig. 19), and the other is the $Y$-class cell on account of the presence of the $Y$ in it (Fig. 20), the total number of the chromosomes on each side being fifteen. 
Remarks:- The chromosome number observed in the present species, Hydrous acuminatus, is quite in accord with that reported by Arnold ('08) for Hydrophilus piceus, both species being the members of the same sub-family Hydrophilinae. A closer comparision of the morphological characters of the chromosomes of these two species is impossible, because no figures nor description have been given by Arnold ('08) for Hydrophilus. Moreover, Arnold ('08) offers no evidence concerning the sex chromosomes, though the even number of chromosomes in the species he has investigated is suggestive of the possibility of the presence of the $\mathrm{XY}$ as in the present material. Arnold ('08) describes that in the first division, in addition to $\mathbf{1 5}$ gemini, there is another chromosome-like body which he identifies as the nucleolus which goes undivided to one pole in the first division. The account given by Arnold ('08) seems to lack in accuracy and we believe a renewed investigation of that material is necessary.

\section{Family Buprestidae}

The investigations on the chromosomes of the buprestid beetles are so far limited to three species with unsatisfactory results. Stevens ('06) gave a brief account of the sex chromosomes in two species of the spruceborer (species names not given). A little later Nichols ('10) studied the chromosomes of Euchroma gigantea and described the behaviour of the $\mathrm{XY}$ complex in the first division, illustrating it with a configuration which is very doubtful. In the present study the chromosomes of three species are dealt with, in all of which a new evidence regarding the permanent attachment of the $\mathrm{X}$ chromosome to an autosome to form a multiple chromosome, as occurs in some acridian species such as Hesperotettix and Mermiria (McClung '17), has been obtained.

\section{Sternocera nitidicolis}

The size of the germ cells in this species is comparatively larger than in those of the previous species already studied. The chromosomes are accordingly larger and distinct enough to admit of a detailed morphological analysis. The diploid number of chromosomes, as counted in the spermatogonial cell, was determined without any doubt to be constantly 26 (Figs. 21-22). The chromosomal garniture here is quite motley, as Vshaped and rod-shaped elements with varying lengths constitute the complement. A careful examination shows that the diploid complex consists of three prominently large V-shaped elements $(a, a, b$ in Fig. 21), a single very long rod $(c)$, eight small V-shaped bodies ( $d d, e e, f f, g g$ ) and the remaining 14 short rod-shaped chromosomes, showing a slight gradation in length. Of the three large V's, two $(a, a)$ are a little larger than the third one $(b)$, and they are quite similar in shape and size, having a nearly median attachment. These two V's undoubtedly con- 
stitute a homologous pair. The remaining one $(b)$, being a little smaller in size and showing a submedian attachment has no mate and remains unpaired. It is evident from their shape and size that eight small $V$ shaped chromosomes constitute four fairly homologous pairs, all being nearly submedian in structure. One of these pairs $(g, g)$ is constituted by two bodies, which look like two satellited chromosomes, as each of them shows a deep constriction, being thus divided into a long arm and a short knob, these two parts remaining connected by a fine fibre. The
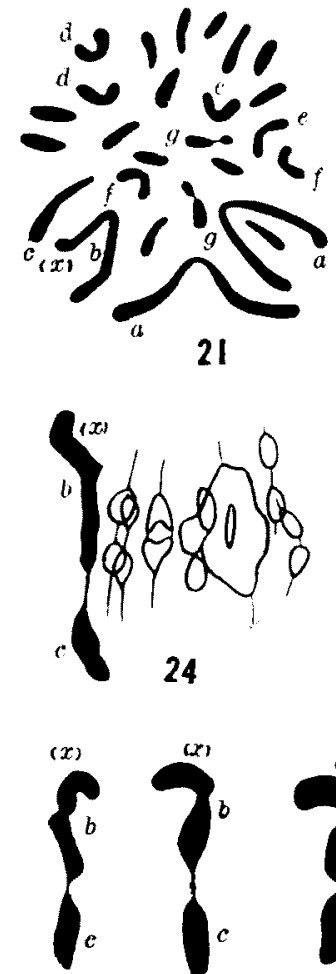

27

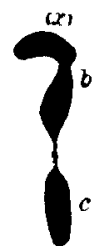

28

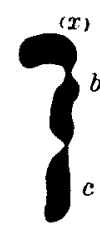

29
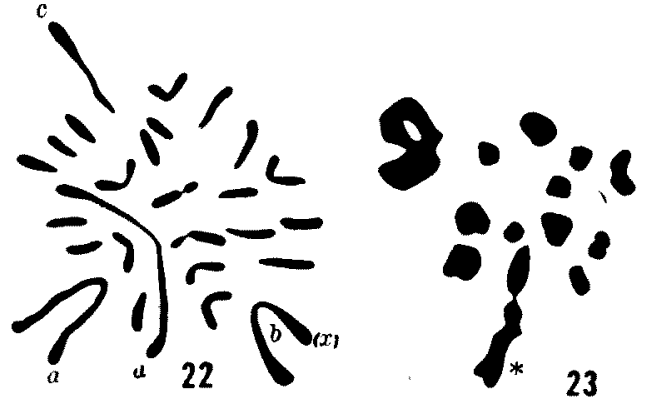

23

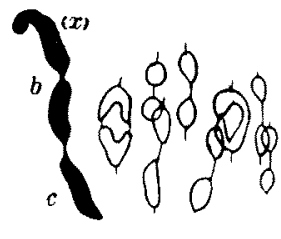

25

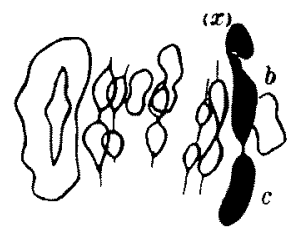

26

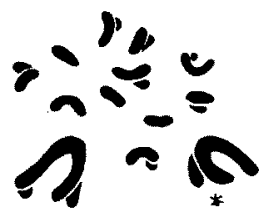

31

Figs. 21-31. Chromosomes of Sternocera nitidicolis. $\times 3700,21-22$, Spermatogonial metaphases. $b$; V-shaped multiple including the $\mathrm{X}$ element $(x)$. 23, Primary spermatocyte metaphase. *; hexad multiple. 24-26, Side views of the primary spermatocyte metaanaphases, A hexad multiple is shown in solid black. 27-29, Hexad multiples in the primary spermatocyte metaphase. 30, Secondary spermatocyte metaphase, no X-class. 31, The same, X-class. A V-shaped multiple including the $\mathrm{X}$ is indicated by an asterisk.

14 telomitic rod-shaped elements are grouped into seven pairs of homologous chromosomes. They form a closely related series showing a slight diminution in length. It is noticeable here that in two very conspicuous unpaired elements, a large submedian $V(b)$ and a long rod $(c)$, the long arm of the $V$ fairly corresponds to the long rod element $(c)$ in its shape and size. 
There are observable 13 chromosomes in the primary spermatocyte metaphase (Fig. 23), of which 11 are bivalent in nature and are comparatively small varying in shape and size. These are ordinary tetrads descended from four pairs of small atelomitic chromosomes and seven pairs of rod-shaped ones. Of the remaining two, one is a large compound $V$-shaped tetrad lying on the periphery, which is the bivalent originating from a homologous pair of the largest V's $(\alpha a)$ in the diploid complex and the other is a peculiar shaped chromosome (* in Fig. 23) formed by the association of a $\mathrm{V}$-shaped element $(b)$ with a long rod $(c)$, the latter two remaining in an unpaired condition in the diploid complement. This heteromorphic chromosome is formed by the attachment of the free end of the long arm of the $\mathrm{V}(b)$ to one end of the long rod $(c)$, the latter corresponding in size to the former, resulting in an end-to-end conjugation (Figs. 24-29). At first sight it may seem to be true that the large $\mathrm{V}$ of this complex, the ' $b$ ', is the $\mathrm{X}$ chromosome and its partner, the long rod-shaped element, the ' $c$ ', may be regarded as the $\mathrm{Y}$ chromosome. In order to see whether this. view is correct we may trace the history of this heteromorphic element right up to the prophase of the primary spermatocyte. In the earlier stages of the meiotic prophase one arm of the $V$ element remains entirely condensed being subjected to heteropycnosis just in the manner of the $\mathrm{X}$ chromosome in the ordinary case, whereas the other arm assumes a diffused, granular appearance as it generally happens in the case of the autosomal chromosomes. In diakinesis the entire body of the heteromorphic element becomes condensed. This represents its whole structure composed of the $\mathrm{V}$-shaped element and the long rod-shaped body united with it end-to-end. From these observations in the meiotic prophase, as noted above, one may justifiably infer that, that arm of the $\mathrm{V}$ which goes through heteropycnosis in earlier stages is the free shorter arm and this free short arm of the $V$ is the real $\mathrm{X}$ chromosome. Consequently the whole $\mathrm{V}$ under consideration (the $b$-chromosome) is a multiple chromosome resulting from the union of a long rod-element, at one of its extremities, with a little shorter element, the $\mathrm{X}$ chromosome. This union probably takes place at the points of the fibre attachment of both the chromosomes thus producing the large $\mathrm{V}$ shaped heteromorphic element. On the basis of this fact, therefore, the following statement is warranted that the heteromorphic element found in the primary spermatocyte is not the XY complex, but a hexad multiple; which is constituted by the union of two long rod-shaped dyads with a rod-shaped $\mathrm{X}$ element, the latter being a little shorter than the two former bodies. Thus this offers another instance similar to cases already known in several orthopteran species such as Hesperotettix and Mermiria (McClung '17).

The association of the $\mathrm{X}$ with the autosome mentioned above is a 
permanent condition for this species. In the first division segregation takes place between the V-shaped multiple and its associate, the long rod. when the other ordinary tetrads divide (Figs. 24-26). As a result two classes of the secondary spermatocytes are produced though the number of chromosome is thirteen in the representatives of both the classes. In one of these two classes of cells, however, there are a large $\mathrm{V}$, a long rod, both of which are very prominent elements, and 11 smaller dyads (Fig. 30 ), while a cell representing the other class of secondary spermatocytes contains two V-shaped elements, one of which is the V-shaped multiple including the $\mathrm{X}$, and a similar set of 11 smaller dyads (Fig. 31).

Summarizing the foregoing description it may briefly be stated that there are 26 chromosomes in the spermatogonium, two of which having no homologues remain in the unpaired condition and are quite remarkable in shape and size. One of them is a $V$-shaped element submedian in its attachment and the other is a long rod-shaped body, which corresponds in size to the long arm of the former $V$. The $V$-element is proved to be a multiple chromosome resulting from the attachment of a long rodshaped autosome to a little shorter rod, the $\mathrm{X}$ chromosome, they being united end-to-end at their points of fibre attachment. In the primary spermatocyte the two elements, the $V$ and the long rod, constitute a hexad multiple by the conjugation of the $\mathrm{V}$ with the long rod. The association of the $\mathrm{X}$ to the autosome is permanent in this species. As a consequence of the separation of the hexad into the $V$-shaped multiple, involving the $\mathrm{X}$, from its associate the long rod in the first division, there are produced two sorts of secondary spermatocytes, one of which contains the multiple $\mathrm{V}$ including the $\mathrm{X}$, and the other the long rod.

The association between the $\mathrm{X}$ and the autosomes has been found in several species of the acridian insects leading to the formation of a multiple of even a higher order than the hexad (McClung '17, King \& Beams '38). But in Coleoptera no corresponding example has yet been found. The present finding, therefore, is the first of its kind described so far in this order.

\section{Sternocera laevigata}

The diploid number of chromosomes in this insect is just the same as in the preceding related species, $S$. nitidicolis, that is, there can be counted 26 chromosomes in the spermatogonial metaphase (Figs. 32-33). In this diploid complement three V-shaped chromosomes $(a, a$ and $b)$ and a rod-shaped member $(c)$ are conspicuous by their large size, and in this feature they show a striking contrast to the other chromosomes as in the case of the former species. The remaining 22 chromosomes are uniformly smaller in this species as compared with those of the former species. In a well-preserved condition eight of them seem to be con- 
stricted, being slightly bent, suggesting their atelomitic nature, as was the case with the former species. Thus there is a close similarity between this two related species, laevigata and nitidicolis, in the number and morphological characteristics of the chromosomes. The only difference between them seems to exist in the fact that the small 22 chromosomes are uniformly shorter and more slender in laevigata than in nitidicolis.

The four large chromosomes, three V's and one rod, deserve a more detailed consideration in this species also. Two out of the three V's are quite similar in shape and size to each other being nearly median in attachment and they form a homologous pair ( $a$ a in Figs. 32-33). The
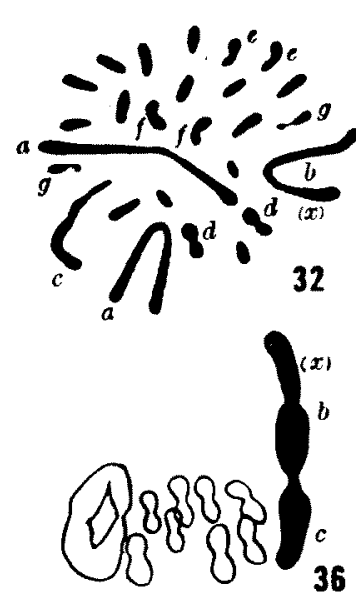
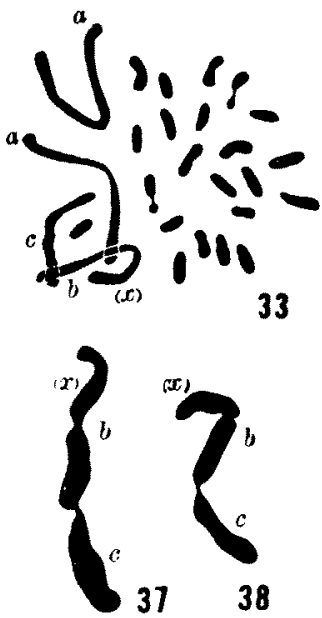
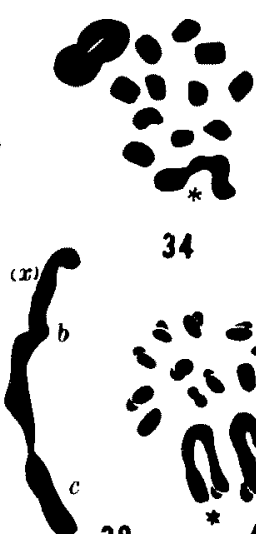

34

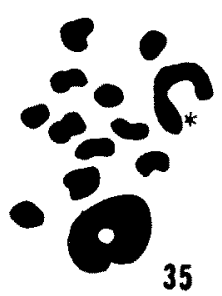

35

Figs. 32-11. Chromosomes of Sternocera laevigata. $\times 3700.32-33$, Spermatogonial metaphases. $b$; V-shaped multiple including the $\mathrm{X}(x)$. 34-35, Primary spermatocyte metaphases, *; hexad multiple. 36, Side view of the primary spermatocyte meta-anaphase. A hexad multiple is shown in solid black. 37-39, Hexad multiples in the primary spermato. cyte metaphase. 40, Secondary spermatocy te metaphase, containing the V-shaped multiple $\left(^{*}\right)$ including the attached $X .41$, The same, no X-class.

remaining one $(b)$ shows a submedian attachment and lies unpaired in the complex. The long arm of this $\mathrm{V}$ corresponds in size to the long rodshaped chromosome $(c)$ which also is unpaired in the complex. From these observations and also from the findings in the former species, one may safely conclude that the solitary submedian $\mathrm{V}$, the $b$-chromosome, is a multiple chromosome produced by the association of the shorter rod: the $\mathrm{X}$ element, with the longer rod, an autosome, which is the partner of the long unpaired, rod-shaped chromosome, the $c$-element. Thus, as regards this condition, the present species is quite in accord with $S$. nitidicolis.

The primary spermatocyte metaphase shows 13 chromosomes among which two are conspicuously large-sized (Figs. 34-35). Of these two large elements, one is the compound V-shaped tetrad formed by the synapsis of the two homologous largest V's. The other is a hexad 
multiple arising from the conjugation of the multiple $\mathrm{V}$ (the b-chromosome) with the long solitary rod (the c-chromosome), the free extremity of the long arm of the $\mathrm{V}$ and one of the two ends of its probable homologue, the long rod, coming to be attached to each other (Figs. 36-39). In the first division the association between the multiple $\mathrm{V}$ (with the attached $\mathrm{X}$ ) and the long rod terminates, and this results in the formation of two kinds of secondary spermatocytes differing from one another with regard to the distribution of the multiple $\mathrm{V}$ and the long rod. All the secondary spermatocytes uniformly possess 13 chromosomes, but in one group of these cells there is found the multiple $V$ containing the attached $\mathrm{X}$ besides 12 chromosomes (Fig. 40 ), while in the other these 12 autosomal chromosomes are accompanied by the long rod-shaped autosomal element instead of the multiple V (Fig. 41).

The attachment between the $\mathrm{X}$ and the autosome to form a multiple seems to be a permanent condition in this species also as in the previous case, and no variation was found in any of the individuals we have examined.

\section{Julodis whithilli}

The general chromosomal condition of this species is somewhat different from what obtained in the former two species belonging to Sternocera. The diploid number of chromosomes observed in the spermatogonial division is invariably 24 (Figs. 42-43), two less than the number found in the species of Sternocera mentioned above. The chromosomal garniture of $J$. whithilli consists of five large V-shaped, one remarkably long rodshaped chromosomes. Among the five large V's, two (a a) are comparatively larger than the other two $(b \quad b)$ which are a little smaller, all being subterminal. They have similar shape and size two by two. These four chromosomes can thus be sorted out into two homologous pairs. The remaining $\mathrm{V}$-shaped element $(c)$ has two dissimilar arms, one longer than the other, and there exists no corresponding mate to it in the complement. The long arm of this $\mathrm{V}$ element corresponds in length, shape and size to the remarkably long rod-shaped chromosome $(d)$, which also is unmated in the complex. From the observations on the primary spermatocytes, subsequently mentioned, and also from the evidence furnished by the two species of Stemocera, referred to above, it may almost certainly be said that this unpaired $V$-shaped element $(c)$ is a multiple chromosome produced by the union of a short rod, the X-chromosome, with a long rod which is the homologous mate of the solitary long rod-like element $(d)$. It is interesing to note that this inference is well confirmed by the fact that a slender fairly long thread is distinctly visible connecting the $\mathrm{X}$ and the long rod end-to-end (see Figs. 42-43, $c$ ).

Eighteen short rod-shaped chromosomes, all approximately equal in their length, form a graded series. One element among them is quite 
remarkable in having a satellite-like minute body connected with it by a fibre at its inner end. It is curious that no corresponding element of such a nature can be found in this complement.

In the first division there are seen at metaphase 12 chromosomes (Fig. 44). Among them three, because of their strikingly large size, stand

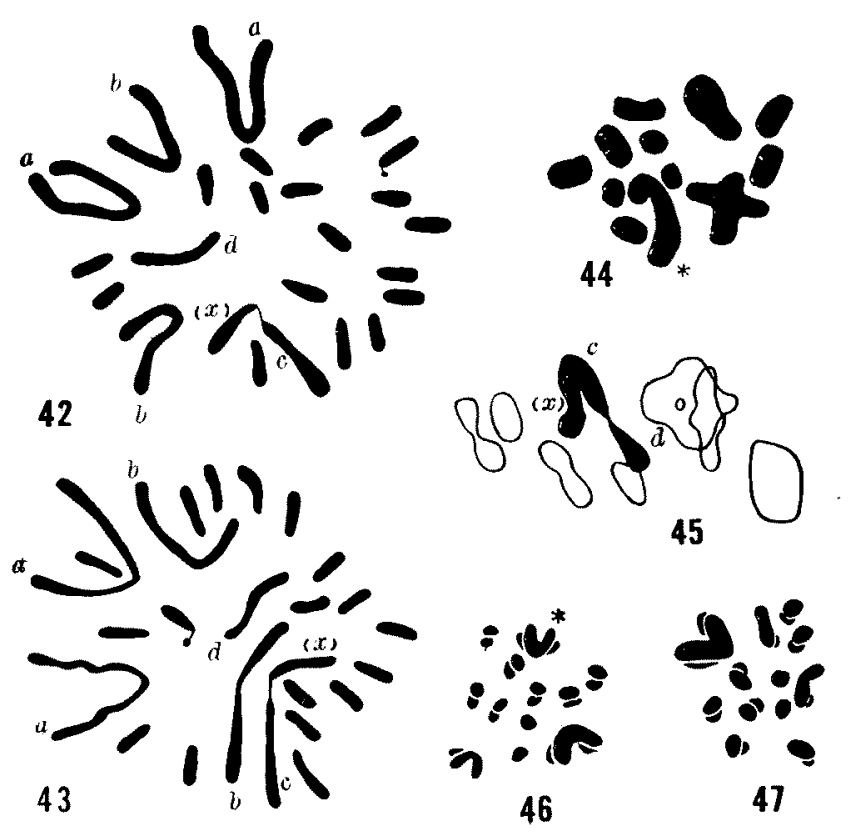

Figs. 42-47. Chromosomes of Julodis whithilli. $\times 3700 . \quad 42-$ 43, Spermatogonial metaphases. $c$; V-shaped multiple involving the $\mathrm{X}(x)$. 44, Primary spermatocyte metaphase. *; hexad multiple. 45, Side view of primary spermatocyte metaphase. A hexad multiple is shown in solid black. 46, Secondary spermatocyte metaphase, containing $V$-shaped multiple $\left(^{*}\right)$ including the $X .47$, The same, no $X$-class. out conspicuously in contrast to the others. Two out of these three elements are compound V-shaped tetrads, derived from the four large $V$ elements of the spermatogonial cell. The remaining one is the hexad produced as a result of conjugation between the $V$-shaped multiple (c), involving the attached $\mathrm{X}$, and the long rodshaped chromosome $(d)$, as has already been observed in the former two cases (Fig. 45). The segregation of the hexad into its two components, the multiple $\mathrm{V}$ and the long rod, in the first division, results in the formation of two sorts of secondary spermatocytes. Though the number of chromosomes is twelve in each case, one of them possesses the V-shaped multiple including the $\mathrm{X}$ (Fig. 46) and the other contains the long rod instead of the multiple $V$ (Fig. 47).

The attachment of the $\mathrm{X}$ to the autosome seems to be constant in this species also, and no variation occurs among the individuals examined just as in the case of the two species of Sternocera. Thus it is of considerable interest to record that all the three species belonging to the family Buprestidae studied here, uniformly show the presence of the multiple $\mathrm{X}$ chromosome which varies but little in its structure and composition in these three species.

Remarks:- Prior to the present investigation, the chromosomes of 
barely three species of the family Buprestidae have been recorded in the literature. Stevens ('06) reported upon the sex chromosomes of two species of the spruce-borer (species names not given), showing the presence of the XY condition in them. In his study on Euchroma giganta. Nichols ('10) observed 13 chromosomes in the primary spermatocyte giving the $\mathrm{XY}$ configuration in a side view of the spindle, though the figure presented by him is not sufficiently convincing.

So far as the authors are aware prior to this study there has not appeared in the literature on the chromosomes of Coleoptera any case in which the coupling of the $\mathrm{X}$ with one of the autosomes forming a multiple chromosome is described. It is for this reason perhaps that this pioneer record of the existence of a multiple chromosome involving the $\mathrm{X}$ appearing with such a remarkable uniformity in these 3 Indian species of Coleopterous insects may prove of some value. Against this statement the only solitary instance we know of is the case of Blaps furnished by Nonidez ('15, '20) and Wilson ('25), who, however, in their individual studies on the chromosomes of this insect offer conflicting views in this direction. This case of Blaps will again be referred to in a subsequent section in this paper.

\section{Suborder ADEPHAGA}

\section{Family Carabidae}

Our knowledge of the chromosomes in this family extends so far to seven species of which three were studied by Carnoy ('85) and the remaining four by Stevens ('06). The following section embodies an account of the chromosomes of Anthia serguttata.

\section{Anthia sexguttata}

The components of the diploid complement are rather variegated in shape and size falling into two main groups, V-shaped elements varying in size and minute spheroidal bodies. The number of chromosomes is fairly high. After a careful examination of several equatorial plates it was ascertained that 35 chromosomes formed the spermatogonial complex (Figs. 48-49). This complement consists of $33 \mathrm{~V}$-shaped chromosomes and 2 minute spheroidal ones of equal size, thus making a complex containing an odd number. By pairing the homologous mates it was determined that the $\mathrm{X}$ chromosome is represented by a medium-sized element submedian in structure. The $\mathrm{X}$ displays no special characteristics to make it distinguishable from the other chromosomes, and therefore it is by no means easy to point it out with certainty in the diploid garniture.

In the primary spermatocyte metaphase 18 chromosomes are found (Fig. 50). In consonance with their rather striking variation in size which they show in the diploid complex, the chromosomes of the primary 
spermatocyte too vary markedly in the same feature. They constitute 17 bivalents derived from autosomal elements and there is a univalent $X$, which appears in the form of a condensed V (see $x$ in Figs. 51-52). The $\mathrm{X}$ goes ahead of others in the first division, migrating earlier to one of the two poles (Figs. 51-52). The secondary spermatocytes thus produced

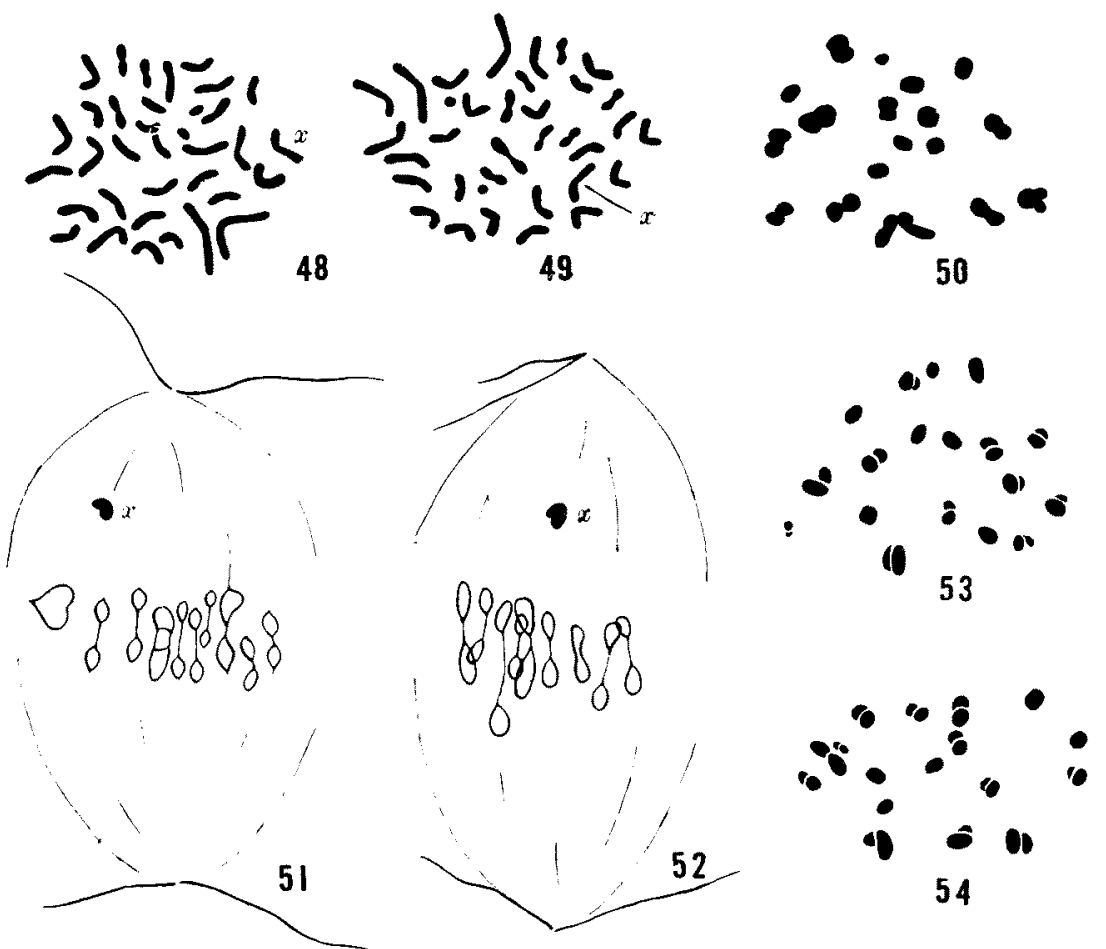

Figs.'48-54. Chromosomes of Anthia sexguttata. $\times 3700.48-49$, Spermatogonial metaphases. 50, Primary spermatocyte metaphase, 51-52, Side views of the spindle of the primary spermatocy te meta-anaphase. Note the $V$-shaped centriole. 53, Secondary spermatocyte metaphase, X-class. 54, The same, no X-class.

are of two sorts as regards the presence or absence of the $\mathrm{X}$ element, giving the chromosome numbers 18 (Fig. 53) and 17 (Fig. 54) respectively.

This species furnishes another interesting instance where the elongated V-shaped centrioles are cbservable at the two poles of the spindle in the first division (see Figs. 51-52). In its structure and general features, this $\mathrm{V}$-shaped centriole does not show any marked deviation from the centrioles of a similar nature found in Lepidoptera.

Remarks:- The chromosomes observed in seven species representing six genera of the family Carabidae have been reported upon in two papers, one by Carnoy ('85) and the other by Stevens ('06). Adding the present report to those already existing one finds that the chromosomes in this 
family show a remarkable variation in number, ranging from the lowest probable 16 to 38 . The observations made by Carnoy ('85) on Harpalus, Procrustes and Feronia are not quite convincing. Stevens ('06), however, in a paper on the chromosomes of the following four species, Anomoglossus emargimatus, Chlaenius aestivus, Ch. pennsylvanicus and Galevita bicolor reports that the sex-determining mechanism is of the XO type in Anomoglossus as in the present case, Anthia, while the XY arrangement exists in the other three species. It is evident, therefore, that two different types of the sex-determining mechanism seem to prevail at present among the species of this family so far studied. Beyond these observations on the sex chromosomes, no further comparative study on the morphological characters of the chromosomes of these species is possible, as in most cases accurate observations and a detailed description are not available:

The appearance of the $V$-shaped centrioles in the primary spermatocytes may perhaps lend further interest to this short study on the chromosomes of Anthia. Fairly long filaments unite at one end to form these $V$-shaped centrioles as they do in Lepidoptera. In general appearance these centrioles differ from those found in some Orthoptera, Neuroptera and Chelonia where thick or thin, rod-like arms are observable (cf. Kichijo '40). Such V-shaped centrioles have been described in Coleoptera by earlier authors in the following species, Feronia, Harpalus, Hydrophilus (von Korff '01), Cybister (Voinov '03) and Dytiscus (Schafer '07).

\section{General remarks on the chromosomes of Coleoptera}

The order Coleoptera is divided into two suborders, Adephaga and Polyphaga. The number of families in which the chromosomes have been studied more or less in detail is three in Adephaga and 20 in Polyphaga. In the adjoining table will be found the names of the families and the number of species in each family in which chromosomal investigations have been carried out, including those which have been dealt with in this paper. As shown in the table and as far as could be ascertained by reference to literature up-to-date upwards of 123 species have been covered by these studies. Sixty nine of these species have been mentioned in the well-known lists compiled by Harvey in 1916 and 1920. Subsequent to the publication of these lists the following authors have carried out further investigations on the chromosomes of this group of insects: Brauer '28, Bushnell '36, Galan '31, Goldsmith '19, Hayden '25, McMullen '28, Minouchi '35, Nonidez '20, Shaffer '20, Scott '36, Strasburger '36, Suomalainen '40a, b, Tiegs and Murray '38, Toshioka \& Yamamoto '37, 
the present authors and some others. ${ }^{1,2}$ In the number of its species on the chromosomes of which researches have been carried out as shown by this fairly long list, Coleoptera can well stand comparison with other orders such as Orthoptera, Hemiptera and Lepidoptera in which such researches have been extended to a very large number of species.

Table 1. Showing the families of Coleoptera and the numbers of species, included in each family, in which the chromosomes have been studied.

\begin{tabular}{l|c}
\hline \multicolumn{1}{|c|}{ Families } & $\begin{array}{c}\text { Number of stud- } \\
\text { ied species }\end{array}$ \\
\hline Adephaga & \\
Carabidae & 8 \\
Cicindelidae & 3 \\
Dytiscidae & 5 \\
Polyphaga & \\
Bruchidae & 2 \\
Buprestidae & 6 \\
Cantharidae & 4 \\
Cerambydae & 3 \\
Chrysomelidae & 27 \\
Coccinellidae & 8 \\
Cucujidae & 1 \\
Curculionidae & 18 \\
Elateridae & 3 \\
Hydrophilidae & 2 \\
Lampyridae & 4 \\
Lucanidae & 1 \\
Melandryidae & 1 \\
Meloidae & 4 \\
Micromalthidae & 1 \\
Passalidae & 1 \\
Scarabaeidae & 11 \\
Silphidae & 3 \\
Staphylinidae & 4 \\
Tenebrionidae & 3 \\
\hline Total 23 & 123 \\
\hline . & \\
\hline Tation & \\
\hline
\end{tabular}

For a general review of the chromosome studies in the various families of Coleoptera readers may refer to a recent paper by Suomalainen ('40b). This review of observed cases makes it clear that the number of chromosomes in Coleoptera varies according to species from 12 to 44 $(2 n)$. The lowest number 12 was observed in Calandru oryzae (Curculionidae) and in three species of Scarabaeidae. The highest one, 44, was obtained in Staphylinas violaceus (Staphylinidae) and Otirrhynchus scaber (Curculionidae), the most frequent number being 20 , about $30 \%$, and 22 , being next common about $17 \%$. In conformity with this variation in chromosome numbers the karyotypes of Coleoptera are also found varying in quite a wide range. Inconstancy either in the number of chromosomes or in the chromosomal constitution within a single family is commonly found.

Of particular interest is the case of parthenogenetic curculionids (weevils) recently studied by Suomalainen ('40a, b) in which triploid and tetraploid species have been found. In Curculionidae parthenogenesis is not uncommon. According to Suomalainen ('40a, b), the chromosome numbers of parthenogenetic species are an arithmetic series, 22,33 and 44 . Since the diploid number of the bisexual species is 22 , it is evident that among the parthenogenetic species there occur triploid and tetraploid species in addition to the diploid ones.

1 The papers by Brooks (Univ. Okla. Biol, October 1922: 32-55), Chudoba (1933, Comp. Rend. Sea, Biol. 113: 195), Geroilsky (1930, Proc. U.S.S.R. Cong. Genet. 2: 205-217), Karpov (Axch. Russ. Anat. Hist. Embr. 5: 137-143), Snyder (1934, Proc. Penn. Acad. Sci. 8: 50-51), we regret, have not been referred to in this paper, as they were not accessible to us.

"The very helpful list of chromosome numbers compiled by Dr. McClung ('39) unaccountably leaves out references to some recent researches on the chromosomes of Coleoptera including those reports on the same subject which have appeared in American publications. 
All the cases recorded are in agreement in furnishing the evidence that the male is heterogametic as regards sex. Though no complete analysis of sex-determining mechanism has yet been made, looking over the cases so far investigated, three types of sex-chromosomes seem to occur in Coleoptera.

1) The XO condition. This type has been described in the males of a number of different species. Generally the $X$ runs to one pole in the first division. The coupling of the $\mathrm{X}$-chromosome with one of the autosomes thus forming a multiple chromosome has been found in three species of Buprestidae investigated here.

2) The XY condition. This is the type most commonly met with in male beetles. The $\mathrm{X}$ usually segregates from the $\mathrm{Y}$ in the first division, $X$ and ' $Y$ going to opposite poles. In most cases, the size difference between the $\mathrm{X}$ and $\mathrm{Y}$ is remarkable, the latter being conspicuously small.

3) The compound $X$. The presence of a compound $X$ composed of two components has been described in Cicindela and Leptinotarsa. But these findings are not sufficiently convincing, because another investigator reports that in both these cases the simple XY arrangement occurs.

In this connection an interesting phenomenon is met with in the case of Blaps lusitanica. According to Nonidez ('15, '20), the male has the sex determining mechanism of the XO type, but four autosomes come to associate with the $\mathrm{X}$ during the primary spermatocyte stages. In the first division, the $\mathrm{X}$ and three of its associated elements go to one pole, while the remaining associate migrates to the opposite pole. In contrast to this view Wilson ('25) thinks that in this case the compound $\mathrm{X}$ really consists of four components which associate with a large $\mathrm{Y}$ in the primary spermatocyte. Schrader's ('28) comments on this case are that the interpretation offered by Wilson ('25) would seem to be a more natural one in view of the fact that one large chromosome (Wilson's Y) always goes to the pole opposite to that which receives the remaining four heterochromosomes.

\section{Summary}

The chromosomes of seven Indian forms of beetles (Coleoptera) were investigated in their male germ cells, with special reference to the morphology of the sex chromosomes. The material studied and the results of observations are summarized in the table given below.

In every case studied the sex chromosomes segregate reductionally in the primary spermatocyte division.

The multiple chromosome which involves the unpaired $\mathrm{X}$ chromosome was found in three species of Buprestidae. The rod-shaped $\mathrm{X}$ chromosome is associated with a particular rod-shaped autosome (a little longer 


\begin{tabular}{|c|c|c|c|}
\hline \multirow{2}{*}{ Species } & \multicolumn{2}{|c|}{ Number of chromosomes } & \multirow{2}{*}{ Sex chromosome } \\
\hline & $2 n$ & $n$ & \\
\hline \multicolumn{4}{|l|}{ Polyphaga } \\
\hline \multicolumn{4}{|l|}{ Meloidae } \\
\hline $\begin{array}{l}\text { 1. Mylabris pustulata } \\
\text { 2. Meloe sp. }\end{array}$ & $\begin{array}{l}22 \mathrm{spg} \\
20 \mathrm{spg}\end{array}$ & $\begin{array}{l}11(\mathrm{I}, \mathrm{II}) \\
10(\mathrm{I}, \mathrm{II})\end{array}$ & $\begin{array}{l}\mathrm{XY} \\
\mathrm{XY}\end{array}$ \\
\hline \multicolumn{4}{|l|}{ Hydrophilidae } \\
\hline $\begin{array}{l}\text { 3. Hydrous acuminatus } \\
\text { Buprestidae }\end{array}$ & $30 \mathrm{spg}$ & $15(\mathrm{I}, \mathrm{II})$ & $X Y$ \\
\hline 4. Sternocera nitidicolis & $26 \mathrm{spg}$ & $13(\mathrm{I}, \mathrm{II})$ & $\mathrm{XO} ; \mathrm{X}$ attached \\
\hline 5. Sternocera laevigata & $26 \mathrm{spg}$ & $13(\mathrm{I}, \mathrm{II})$ & $\begin{array}{l}\text { to an autosome } \\
\mathrm{XO} ; \mathrm{X} \text { attached }\end{array}$ \\
\hline 6. Julodis whithilli & $24 \mathrm{spg}$ & $12(\mathrm{I}, \mathrm{II})$ & $\begin{array}{l}\text { to an autosome } \\
\text { XO, X attached } \\
\text { to an autosome }\end{array}$ \\
\hline \multicolumn{4}{|l|}{ Adephaga } \\
\hline Carabidae & & & \\
\hline 7. Anthia sexguttata & $35 \mathrm{spg}$ & $\begin{array}{l}18 \text { (I) } \\
17,18 \text { (II) }\end{array}$ & Xo \\
\hline
\end{tabular}

than the $X$ ) in the form of an end-to-end attachment, forming a V-shaped multiple, as known in some acridian species. The attachment is permanent for the species and no variation was found among the individuals.

\section{Literature Cited}

Arnold, G. 1908. The nucleolus and microchromosomes in the spermatogenesis of Hydrophilis piceus L. Arch. Zellf. 2.

Brauer, A. 1928. Spermatogenesis of Bruchus quadrimaculatus (Coleoptera : Bruchidae) Jour. Morph. 46.

Bushnell, R. J. 1936. The development and metamorphosis of the mid-intestinal epithelium of Acanthoscelides obtectus Say. Jour. Morph. 60.

Carnoy, J. B. 1885. La cytodierrese ehez les Arthropodes. La Cellule 1.

Galan, F. 1931. Estudio sobre espermatogenesis del Coleoptera Phytodecta variabilis. Los chromosomas en la mitosis gonial y en la reduccion chromosomica. Rev. Espanola Entomol. 7.

Goldsmith, W. 1919. A comparative study of the chromosomes of the tiger beetle (Cicindelidae). Jour. Morph. 32.

Harvey, E. B. 1916. A review of the chromosome numbers in the metazoa. Part I. Jour. Morph. 28.

- 1920. A review of the chromosome numbers in the metazoa. Part II. Jour. Morph. 34.

Hayden, M. A. 1925. Karyosphere formation and synapsis in the beetle, Phanaeus. Jour. Morph. 40.

Henking, H. 1892. Untersuchungen über die ersten Entwicklungsvorgänge in den Eiern der Insekten. Zeits. wiss. Zool. 54.

Kichijo, H. 1940. On the V-shaped centriole in animal cells. (Japanese). Bot. \& Zool. (Tokyo) 8.

King, R. L. and H. W. Beams 1938. The multiple chromosomes of Paratylotropidia brunneri Scudder (Orthoptera : Acrididae). Jour. Morph. 63.

Korff, K. von 1901. Weitere Beobachtungen über das Vorkommen V-formiger Centralkörper. Anat. Anz. Verhandl. Anat. Gesell. 19.

McClung, C. E. 1917. The multiple chromosomes of Hesperotettix and Mermiria (Orthoptera). Jour. Morph. 29.

- 1939. Chromosome numbers in animals. Tab. Biol. 18. 
McMullen, D. B. 1928. Genetical and cytological observations on Oryzaephitus surinamensis (the saw-toothed grain beetle). Amer. Nat. 62.

Minouchi, O. 1936. Über die Chromosomen des Bohnenkäfer Zabrotes subjasciatus Boh. (Bruchidae). Zeits. Zellf. mikr. Anat. 23.

Nichols, M. L. 1910. The spermatogenesis of Euchroma gigantea. Biol. Bull. 19 .

Nonidez, J. F. 1915. Estudios sobre las celulas sexuales. I. Los cromosomas gonalier y les mitosis de maduracion en Blaps lusitanica y Blaps waltli. Mem. Soc. Espan. Hist. Nat. 10.

- 1920. The meiotic phenomena in the spermatogenesis of Blaps, with special reference to the X complex. Jour. Morph. 34.

vom Rath, O. 1892. Zur Kenntniss der Spermatogenese von Gryllotalpa vulgaris Latr. Arch. mikr. Anat. 40.

Schaffer, F. 1907. Spermatogenese von Dytiscus. Zool. Jahrb. 23.

Schaffer, E. L. 1920. A comparative study of the chromosomes of Lachnosterna (Coleoptera). Biol. Bull. 38.

Schrader, F, 1928. The sex chromosomes. Berlin.

Scott, A. C. 1936. Haploidy and aberrant spermatogenesis in a coleopteran, Micromalthus debilis LeConte, Jour. Morph. 59.

Stevens, N. M. 1906. Studies in spermatogenesis. II. A comparative study of the heterochromosomes in certain species of Coleoptera, Hemiptera and Lepidoptera with special reference to sex determination. Carnegie Inst. Publ. 36.

- 1909. Further studies on the chromosomes of the Coleoptera. Jour. Exp. Zool. 6.

Strasburger, E. H. 1936. UUber Störungen der Eientwicklung bei Kreuzungen von Epilachna chrysomerina F. mit. E. capensis Thuen. Zeits. Ind. Abst. Vererb. 71.

Suomalainen, Esko. 1940a. Polyploidy in parthenogenetic Curculionidae. Hereditas 26.

- 1940b. Beiträge zur Zytologie der parthenogenetischen Insekten. I. Coleoptera. Ann. Acad. Sci. Fenn. Ser. A. 54.

Tiegs, O. W. and F. V. Murray 1938. The embryonic development of Calandra oryzae. Q. J. M. S. 80,

Toshioka, S. and T. Yamamoto 1937. A review of the chromosome numbers of Coleoptera. Bot. \& Zool. (Tokyo) 5.

Voinov, D. 1903 . Le spermatogenèse chez Cybister rosellii. Arch. Zool. Exp. Gener. 1.

Wilson, E. B. 1925. The cell in development and heredity. New York. 